\title{
Bimaterial Composites via Colloidal Rolling Techniques: II, Sintering Behavior and Thermal Stresses
}

\author{
Mohan Menon ${ }^{*}, t$ \\ Department of Materials Science and Engineering, University of Michigan, Ann Arbor, Michigan 48109-2136
}

I-Wei Chen ${ }^{*}$

Department of Materials Science and Engineering, University of Pennsylvania, Philadelphia, Pennsylvania 19104-6272

\begin{abstract}
Shrinkage behavior and crack formation during firing have been investigated for $\mathrm{Al}_{2} \mathrm{O}_{3} / \mathrm{Ce}-\mathrm{TZP}$ composites that have been fabricated by colloidal rolling and folding. These composites show improved sinterability and sinter isotropically after repeated rolling. Interface instability in rolling creates corrugated interfaces with large layer waviness; therefore, rolling can substantially alleviate the in-plane sintering constraints, which leads to improved sinterability. A loss of sintering anisotropy also is observed and is directly correlated to the microstructure instability, which is coincident with the laminate-cellular transition. Sintering cracks during heating and thermal cracks during cooling both are limited to the thick Ce-TZP layers in the composites. The critical layer thickness and the normalized crack spacing of the thermal cracks follow the predicted behavior of elasticity theory. Thus, crack-free, high-density $\mathrm{Al}_{2} \mathrm{O}_{3} / \mathrm{Ce}$-TZP composites with either a laminate or cellular microstructure can be obtained, with a layer thickness of 4-60 $\mu \mathrm{m}$, via pressureless sintering.
\end{abstract}

\section{Introduction}

$\mathrm{C}$ OMPOSITES that consist of materials with different sintering behaviors and green densities experience differential shrinkage internally during firing. ${ }^{1,2}$ This difference may lead to internal stresses and residual porosity in the composites. ${ }^{3-12}$ Laminate composites, in particular, have anisotropic sintering behavior in the directions parallel and perpendicular to the layers. Raj and co-workers ${ }^{1,2}$ studied the in-plane and out-ofplane sintering behavior of various multilayered ceramics. They found that the in-plane constraint retarded the sintering rate of the constituent layers. Thus, many researchers have used hot pressing to densify laminate composites. Alternatively, liquid-phase sintering is used, as in the commercial processing of multilayer electronic packages. Furthermore, even monolithic tape may exhibit anisotropic sintering behavior. For example, Nahass et al. ${ }^{3}$ observed such phenomenon in tapes that were cast from aqueous and nonaqueous alumina systems. They attributed the anisotropy to the texturing of alumina powders during the casting process.

Recently, Cai et $a l^{4,5}$ conducted extensive investigations

D. S. Wilkinson—contributing editor

\footnotetext{
Manuscript No. 190323. Received March 16, 1998; approved June 21, 1999.

This research was supported by the U.S. Dept. of Energy (Basic Energy Sciences, BES), through a grant awarded to the University of Pennsylvania (Grant No. DEFG02-97ER45637-A000)

${ }^{*}$ Member, American Ceramic Society.

Now at Dept. of Materials Science and Engineering, University of Illinois, Urbana, IL 61801 .
}

into the development of processing defects in laminates of $\mathrm{Al}_{2} \mathrm{O}_{3}$ and $\mathrm{Ce}$-TZP $\left(\mathrm{CeO}_{2}\right.$-stabilized tetragonal zirconia polycrystals) that were due to sintering constraints and thermal stresses. They concluded that the majority of the defects formed at the beginning of the processing cycle and could be eliminated using slower heating/cooling rates and blended compositions. For $\mathrm{Al}_{2} \mathrm{O}_{3} / \mathrm{Ce}-\mathrm{TZP}$ composites, Ce-TZP is the faster-sintering phase and is under a tensile stress. Therefore, efforts to sinter unblended $\mathrm{Al}_{2} \mathrm{O}_{3} / \mathrm{Ce}$-TZP laminates usually result in some cracking in the $\mathrm{Ce}$-TZP layers. ${ }^{4,6}$ On the other hand, a blended composition of $\mathrm{Al}_{2} \mathrm{O}_{3} / \mathrm{Ce}$-TZP powders instead of pure $\mathrm{Ce}-\mathrm{TZP}$ reduces the differential shrinkage between $\mathrm{Al}_{2} \mathrm{O}_{3}$ and the blended phase, hence reducing the tensile stresses and avoiding cracking. ${ }^{4-10}$ This remedy also can partially alleviate the mismatch in the thermal contraction of different phases..$^{8,9,11-13}$ In $\mathrm{Al}_{2} \mathrm{O}_{3} / \mathrm{Ce}$-TZP composites, the $\mathrm{Ce}$ TZP phase has the higher thermal expansion coefficient. Therefore, Ce-TZP will experience a tensile stress during cooling, causing cracking. ${ }^{8,9,11-13}$ In theory, ${ }^{14}$ cracking that is due to thermal stresses can be eliminated by reducing the thickness of the laminate layer. This phenomenon has been observed in $\mathrm{Al}_{2} \mathrm{O}_{3} / \mathrm{Ce}$-TZP composites by several researchers. ${ }^{8-11}$

In the previous paper (hereafter referenced as paper I), ${ }^{15}$ we described a new family of laminate composites that were fabricated using colloidal rolling techniques. These composites differ from a typical laminate composite in that their phase interface has a tendency to be wavy. Moreover, when the amplitude of the waviness reaches the layer thickness, the laminate transforms to a cellular composite, with one phase enclosed in the other phase. In this paper, the sintering behavior of the laminate and cellular composites is studied and compared with that of a traditional laminate. Shrinkage measurements have been performed on samples of unblended $\mathrm{Al}_{2} \mathrm{O}_{3} /$ $\mathrm{Ce}$-TZP compositions parallel and perpendicular to the rolling direction to evaluate the sintering anisotropy as a function of the composite microstructure. The sinterability was much improved, compared to traditional laminates with flat interfaces. In laminates with thicker layers, where the crack formation in the Ce-TZP layers due to sintering and thermal mismatch did occur, these cracks also were characterized and compared with theoretical predictions. The mechanical properties of these sintered composites will be described in a later publication (referenced hereafter as paper III). ${ }^{16}$

\section{Experimental Procedure}

\section{(1) Materials}

The materials studied here are unblended $\mathrm{Al}_{2} \mathrm{O}_{3} / \mathrm{Ce}-\mathrm{TZP}$ composites that were made from colloidal rolling techniques that have been described in paper $\mathrm{I}^{15}$ The phase fractions of $\mathrm{Al}_{2} \mathrm{O}_{3}$ and $\mathrm{Ce}-\mathrm{TZP}$ are generally the same, and their layer thicknesses vary from $1 \mathrm{~mm}$ to $4 \mu \mathrm{m}$, depending on the number 
of foldings $(N)$ between colloidal rolling. By adjusting the $\mathrm{NH}_{4} \mathrm{NO}_{3}$ salt concentration in the slurry, three sets of samples with different pathways of microstructure evolution have been prepared. Sample $\mathrm{A}$ is composed of $\mathrm{Al}_{2} \mathrm{O}_{3}$ and $\mathrm{Ce}-\mathrm{TZP}$ with comparable rheological flow stress and maintains a planar interface until $N=8-9$; after that point, Ce-TZP has a tendency to be entrapped in an $\mathrm{Al}_{2} \mathrm{O}_{3}$ matrix. Sample $\mathrm{B}$ has a rheologically harder $\mathrm{Al}_{2} \mathrm{O}_{3}$ phase, and its planar interface breaks down after $N=6-7$ and the $\mathrm{Al}_{2} \mathrm{O}_{3}$ is entrapped in the Ce-TZP. Sample $\mathrm{C}$ has a rheologically harder Ce-TZP phase, and its planar interface breaks down after $N=7-8$ and the Ce-TZP is entrapped in an $\mathrm{Al}_{2} \mathrm{O}_{3}$ matrix. The interface instability and microstructure characteristics have been described in paper I. ${ }^{15}$

\section{(2) Shrinkage and Density Measurements}

A dilatometer (Theta Industries, Port Washington, NY) was used to measure shrinkage in the directions parallel $(x)$ and perpendicular $(y)$ to the rolling direction (along and across the layers respectively), as a function of $N$ for sample sets $\mathrm{A}, \mathrm{B}$, and $\mathrm{C}$. The coordinate system referenced previously is the same as that in paper $\mathrm{I}^{15}$ (see Fig. 1 therein). Green samples 2 mm thick were cut from the rolled and dried composites and were ground flat and parallel, using $\mathrm{SiC}$ paper (600 grit), before being loaded in the dilatometer. The samples were heated to $1500^{\circ} \mathrm{C}$ at a rate of $5^{\circ} \mathrm{C} / \mathrm{min}$. The shrinkage and the temperature were monitored using a chart recorder (Cole-Parmer Instrument Co., Chicago, IL). The shrinkage strain and the shrinkage rates were later calculated from the shrinkagetemperature curve after accounting for the initial thickness and the constant heating rate. The shrinkage behavior of rolled $\mathrm{Al}_{2} \mathrm{O}_{3}$ and rolled Ce-ZTP tapes, parallel and perpendicular to the rolling direction, also were characterized, for comparison with the composites.

\section{(3) Density}

The rolled composites were sintered in air at $1600^{\circ} \mathrm{C}$ for $3 \mathrm{~h}$, with a heating/cooling rate of $5^{\circ} \mathrm{C} / \mathrm{min}$. The density of the sintered samples then was measured using the Archimedes principle in distilled water. The scatter of the density data was primarily due to sample-to-sample variation and was on the order of $0.5 \%$.

\section{(4) Crack Measurements}

The microstructures of sintered composites were examined using scanning electron microscopy (SEM), as described in paper I. ${ }^{15}$ Cracks were characterized by measuring the average distance between the neighboring cracks. (Cracks were assumed to be parallel.) The average crack spacing $(L)$ was obtained from at least ten neighboring cracks in the same layer. Then $L$ values were compared, as a function of the layer thickness.

Cracks that are formed during sintering can be readily identified and distinguished from those formed during cooling, because of the very large difference in their crack opening. This point will become clear later in this paper. Therefore, the statistics of these two groups of cracks were evaluated separately.

\section{Results}

\section{(1) Shrinkage}

(A) $\mathrm{Al}_{2} \mathrm{O}_{3}$ and $\mathrm{Ce}-\mathrm{TZP}$, Single Phase: The shrinkage curves of the rolled $\mathrm{Al}_{2} \mathrm{O}_{3}$ and Ce-TZP tapes are plotted in Fig. 1. The shrinkage is smaller in the $x$-direction (parallel to the rolling direction). This anisotropy is more severe in $\mathrm{Al}_{2} \mathrm{O}_{3}$ than in the $\mathrm{Ce}-\mathrm{TZP}$ tapes. The $\mathrm{Ce}-\mathrm{TZP}$ tapes are easier to sinter than the $\mathrm{Al}_{2} \mathrm{O}_{3}$ tapes, because both the sintering curve reaches saturation and the shrinkage rate reaches a maximum at lower temperatures than that for $\mathrm{Al}_{2} \mathrm{O}_{3}$.

(B) $\mathrm{Al}_{2} \mathrm{O}_{3} / \mathrm{Ce}$-TZP Composites: The shrinkage curves for sample A are compared at various $N$ values in Fig. 2. The total volumetric shrinkage, estimated by the sum of the linear
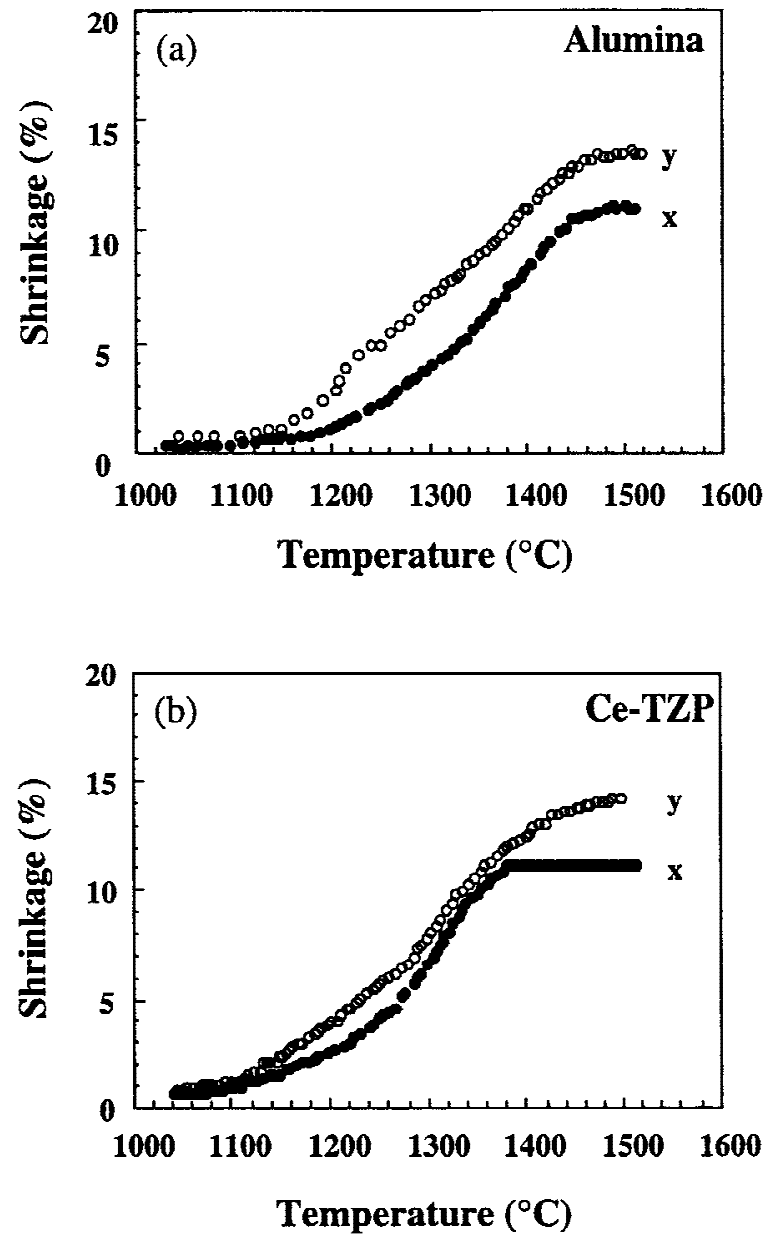

Fig. 1. Shrinkage curves for rolled (a) $\mathrm{Al}_{2} \mathrm{O}_{3}$ and (b) Ce-TZP tapes, showing anisotropic behavior due to rolling operation.

shrinkage in all the three directions $\left(\epsilon_{x}+\epsilon_{y}+\epsilon_{z}=\epsilon_{y}+2 \epsilon_{x}\right.$, assuming $\epsilon_{z}=\epsilon_{x}$, where $\epsilon$ represents shrinkage strain), was approximately what was expected from the green density $(64 \%)$. The shrinkage curve for the tapes in the $x$-direction (rolling) is shifted to a relatively higher temperature than for the $y$-direction (normal to the tape). The final shrinkage values for the two directions also are different (the shrinkage is greater in the $y$-direction). However, the anisotropy systematically decreases as $N$ increases. Similar trends were observed for samples B and C. Ultimately (e.g., after ten foldings), all the shrinkage curves are similar for different samples, although they have different colloidal chemistries and microstructures.

The shrinkage rates for sample A are plotted as a function of temperature for various $N$ values in Fig. 3. These curves confirm the above-noted trend. As $N$ gets smaller, the temperature for the peak shrinkage rate in the $x$-direction becomes considerably higher than that in the $y$-direction. As $N$ increases, the peak temperature in the $y$-direction increases and the anisotropy decreases. Similar behavior has been observed in samples B and $\mathrm{C}$.

The ratio of the shrinkage strain in the $x$-direction $\left(\epsilon_{x}\right)$ to that in the $y$-direction $\left(\epsilon_{y}\right)$ provides a measure of the shrinkage anisotropy after densification, as shown in Fig. 4(a). The temperature at which the shrinkage rate is maximum for both the $x$ - and $y$-directions ( $T_{x}$ and $T_{y}$, respectively) also is compared as a function of $N$ for samples $\mathrm{A}, \mathrm{B}$, and $\mathrm{C}$ in Fig. 4(b). This relationship is an indication of the shrinkage anisotropy at the intermediate densities.

As shown in paper $\mathrm{I},{ }^{15}$ the colloidal chemistry affects the microstructure transition, from a layered to a cellular architec- 

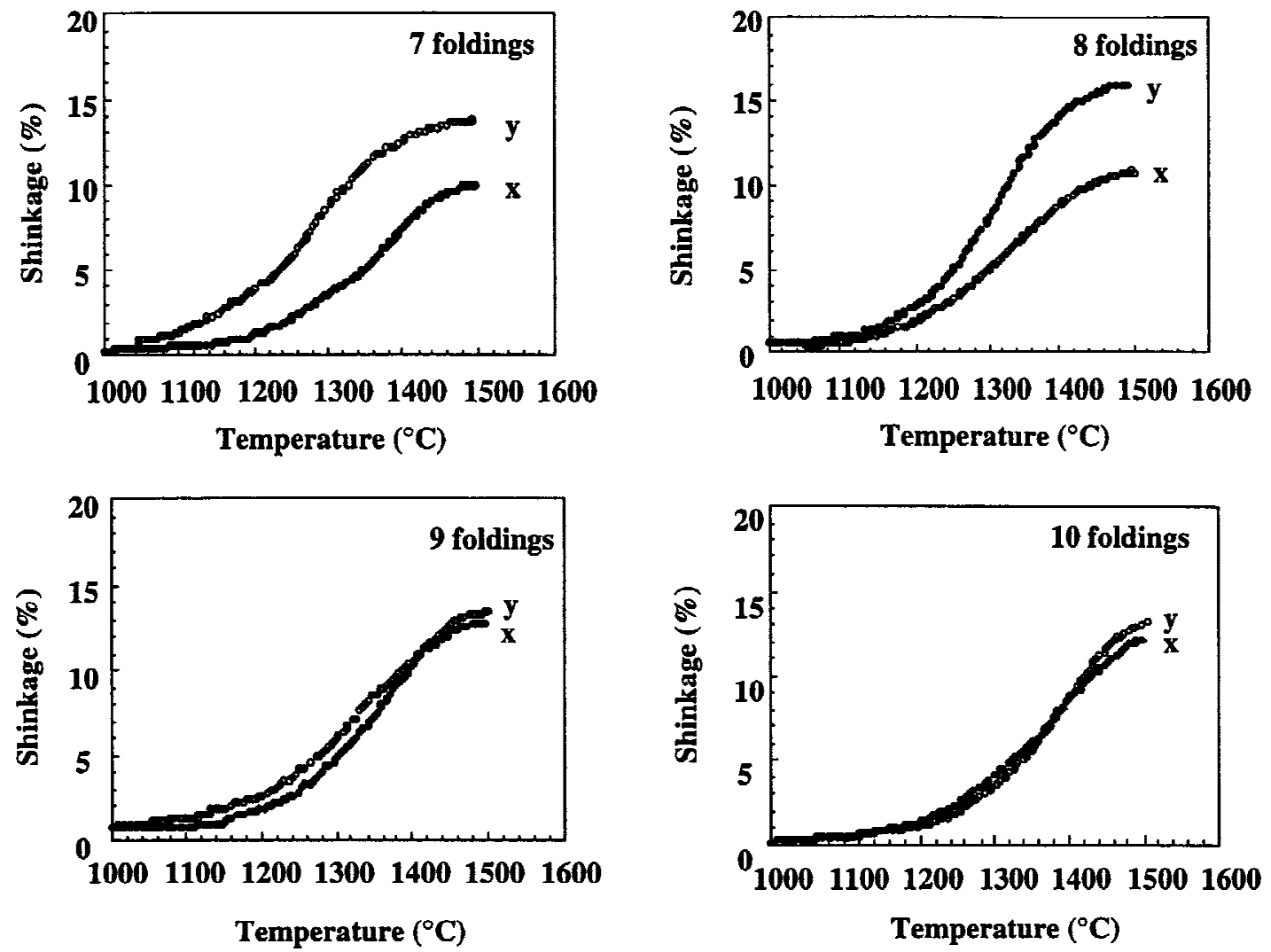

Fig. 2. Shrinkage curves for sample A, as a function of the number of foldings $N$; the anisotropy largely disappears after nine foldings.

ture. Sample A maintains the layered microstructure up to the largest strain $(N=8-9)$, and sample B maintains the layer microstructure up to the lowest strain $(N=6-7)$. Sample $\mathrm{C}$ is intermediate $(N=7-8)$ between samples $\mathrm{A}$ and $\mathrm{B}$, in regard to its rheological properties and resulting microstructure. Systematic differences in the shrinkage behavior also are observed. These differences are best illustrated by Figs. 4(a) and (b), in which the anisotropy persists at higher $N$ (in the order $\mathrm{B}, \mathrm{C}, \mathrm{A}$ ), which is the same number of foldings that are required for the layer-to-cellular transition. Moreover, at the respective $N$ values for this transition, each sample undergoes a rapid reduction of sintering anisotropy in Figs. 4(a) and (b). Thus, a close correlation between sintering behavior and microstructure is established.

\section{(2) Density}

Figure 5 shows the density of the composites as a function of $N$ for samples $\mathrm{A}, \mathrm{B}$, and $\mathrm{C}$. At $1600^{\circ} \mathrm{C}$, all the composites are sintered to almost full density after $N \approx 3$. (The layer thickness was $\sim 450 \mu \mathrm{m}$ at $N=3$ and $\sim 220 \mu \mathrm{m}$ at $N=4$ (see Fig. 5 in paper I).) This observation also is supported by the fact that very little porosity was observed in any of the micrographs reported in paper $\mathrm{I}^{15}$ Note that these composites have unblended $\mathrm{Al}_{2} \mathrm{O}_{3} /$ Ce-TZP compositions for which difficulties in densification have been reported in the literature. ${ }^{4,6}$ Nevertheless, high density has been achieved in our composites. This observation suggests that, although there is different shrinkage behavior between $\mathrm{Al}_{2} \mathrm{O}_{3}$ and $\mathrm{Ce}$-TZP and the composite does experience some internal stresses (as evident from its shrinkage anisotropy), the sintering stress apparently is alleviated to some extent by the microstructure changes that result from repeated folding. This result leads to improved sintering behavior and, eventually, the disappearance of shrinkage anisotropy. (The green densities of the two phases were matched at $64 \mathrm{vol} \%$, so there should be no difference in the final shrinkage between the two phases.)

\section{(3) Cracks}

Figure 6(a) shows the microstructure of sample A folded five times; some cracks in the Ce-TZP layer (brighter phase) are visible. No cracks were observed in the $\mathrm{Al}_{2} \mathrm{O}_{3}$ layers. Two types of cracks were present in the Ce-TZP layers: one has a large crack-opening displacement and sharp black and white contrast, and the other has the appearance of hairline cracks and a faint white contrast. The large crack opening and the rounded edges of the wider cracks indicate that they were formed during sintering. (Closer examination at higher magnification also shows poor matching of the features on the two mating surfaces, as expected for a sintering crack.) On the other hand, the hairline cracks have small crack openings, which indicate that they were formed while the samples were cooled (thermal shock). An extreme case of sintering cracks is shown in Fig. 6(b) for the microstructure of sample B folded once. Notice that the crack-opening displacement of these sintering cracks is as wide as several tens of micrometers. For sample $\mathrm{C}$ folded five times (Fig. 6(c)), only thermal cracks are visible in this region. After the samples were folded six or more times, all these cracks disappeared (see the micrographs in paper I). Also, except in relatively few cases (for example, Fig. 6(a)), the layers that have sintering cracks do not have thermal cracks, and vice versa. This observation means that, after a layer cracked during sintering, it did not crack during cooling. Thus, in very thick layers, typically only sintering cracks were observed. Lastly, because both sintering and thermal cracks largely seem to have tunneled through the Ce-TZP layers without entering the $\mathrm{Al}_{2} \mathrm{O}_{3}$ layers, they will be called "multiple tunneling cracks," following the terminology of thin-film cracking. ${ }^{16}$

To quantify the cracking statistics, Fig. 7(a) shows the mean crack spacing $(L)$, as a function of the layer thickness for sintering cracks. The mean spacing between the cracks decreases (i.e., the crack density increases) as the layer thickness de- 

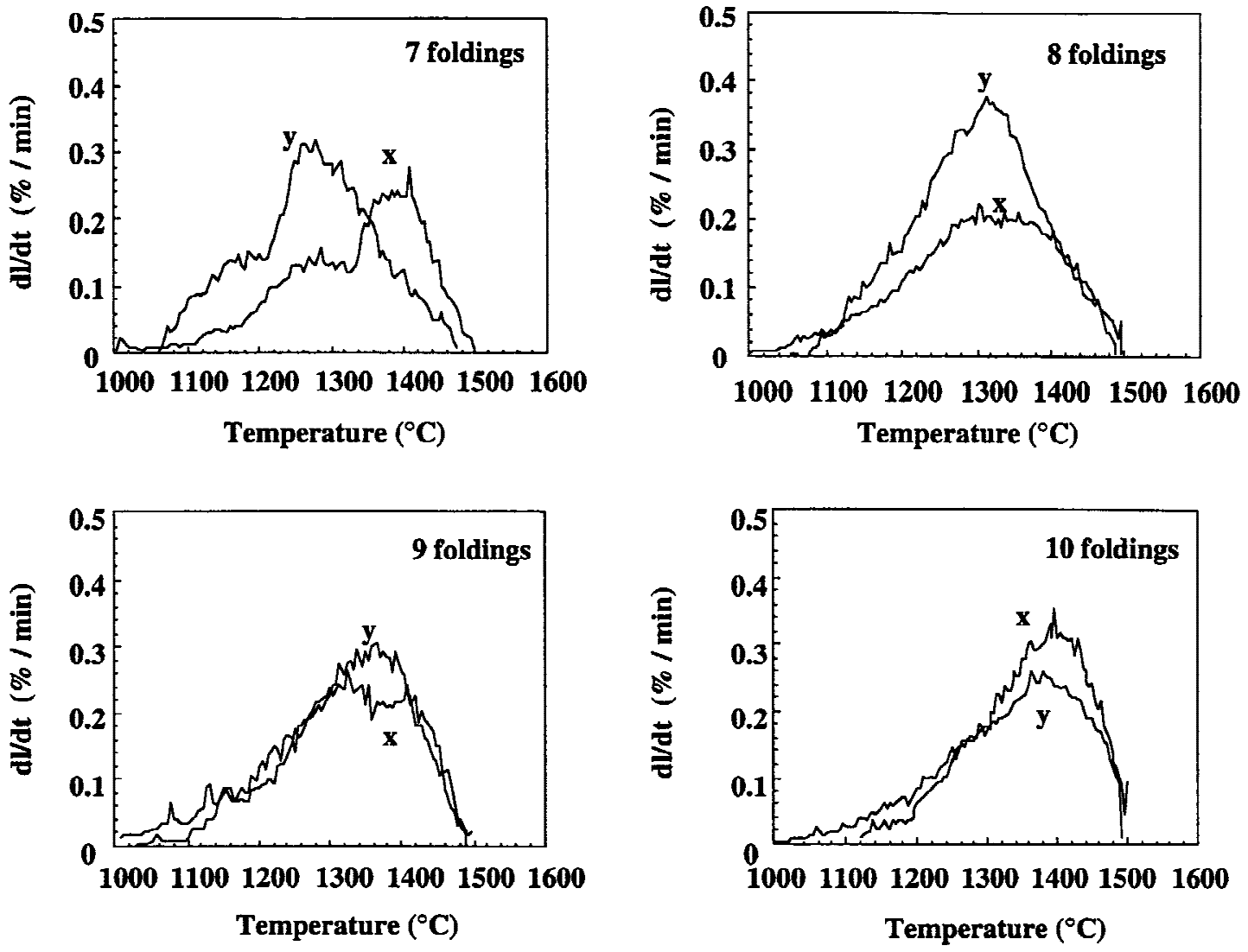

Fig. 3. Shrinkage rate for sample A calculated from Fig. 3, as a function of the number of foldings $N$.

creases. However, the cracks disappear below a critical layer thickness of $\sim 60 \mu \mathrm{m}$. The propensity for cracking was much higher for samples that were folded three times or fewer and decreases in samples with higher $N$ values.

Figure 7(b) shows $L$ as a function of the layer thickness for thermal cracks. Again, no crack was observed below a critical thickness. This critical layer thickness for crack formation was $\sim 50 \mu \mathrm{m}$ and was achievable with six foldings for all samples. For thicker layers, unlike sintering cracks, the crack spacing of the thermal cracks decreases to an asymptotic value of $\sim 170 \mu \mathrm{m}$.

\section{Discussion}

\section{(1) Shrinkage Behavior and Densification}

Given the rather different sintering behavior of rolled $\mathrm{Al}_{2} \mathrm{O}_{3}$ and Ce-TZP tapes, one would expect the sintering of rolled composites using these tapes to be very difficult. Usually, the solution to this problem is to use blended compositions, which relieves the differential shrinkage problem to a large extent. This technique was used by many researchers who make $\mathrm{Al}_{2} \mathrm{O}_{3} / \mathrm{Ce}-\mathrm{TZP}$ laminates. ${ }^{4,6-12}$ Nevertheless, all the composites in this study, regardless of the number of foldings, were able to attain almost full density using pressureless sintering without blended compositions.

As we described in paper $\mathrm{I},{ }^{15}$ colloidal rolling introduces an instability that leads to corrugation of the flat interface between the $\mathrm{Al}_{2} \mathrm{O}_{3}$ and Ce-TZP layers (see schematic in Fig. 8). This interface can be considered to be a blended composition, i.e., a transition layer that is composed of two phases. Within this layer, the differential sintering stress is intermediate between those in the unblended $\mathrm{Al}_{2} \mathrm{O}_{3}$ and Ce-TZP layers (Fig. 8(b)). This condition results in easier sintering of the transition layer. Nevertheless, in the unblended regions outside the transition layers, the layer that has a higher sinterability (Ce-TZP) still experiences the same sintering tensile stress as that previously encountered. This observation can be easily verified from a stress analysis of Fig. 8(b), after strain compatibility between the Ce-TZP layer and the $\mathrm{Al}_{2} \mathrm{O}_{3}$ layer is imposed. Thus, the presence of a blended layer (due to small corrugation of the flat interface) between the unblended Ce-TZP layer and the $\mathrm{Al}_{2} \mathrm{O}_{3}$ layer cannot ensure the good sinterability that is observed.

In addition to small corrugation, the layers in our composites are unique in that they are wavy (Fig. 8(c)). Any straight reference line always intercepts both the alumina and zirconia phases after it travels a certain distance. (See micrographs in paper $\mathrm{I}^{15}$ ) Thus, over a distance that is on the order of the wavelength, the microstructure can be considered to be a blended composite, even if it consists of continuous layers of two materials, and, during sintering, the shrinkage strain along any straight reference line is the sum of the shrinkage strains of two phases. Therefore, while the continuous nature of the layer makes the composite behave as a layered composite, in regard to crack propagation (see paper $\mathrm{III}^{16}$ ), the in-plane sintering stress in the wavy layer is much less than that in a flat layer. Improved sinterability then can be expected in the $x$-direction. Meanwhile, there obviously is very little sintering stress in the $y$-direction in both the wavy composite and the flat composite. The planar connectivity is lost as the layered material breaks down into cellular material (Fig. 8(d)). In the direction perpendicular to the rolling direction, the faster-sintering Ce-TZP phase is not free to shrink anymore and is constrained on all sides by the slower-sintering $\mathrm{Al}_{2} \mathrm{O}_{3}$ phase. This increase in constraint makes the composites more difficult to sinter in the $y$-direction. Indeed, our data show that the maximum shrinkage temperature in the $y$-direction increases as $N$ increases (see Fig. 4(b))

We can use elasticity theory to estimate the different constraints, especially in the two extreme cases that are shown in Figs. 8(a) and (d). (Sintering is actually a viscoelastic problem, but the basic mechanics are similar.) For the sake of simplicity, 

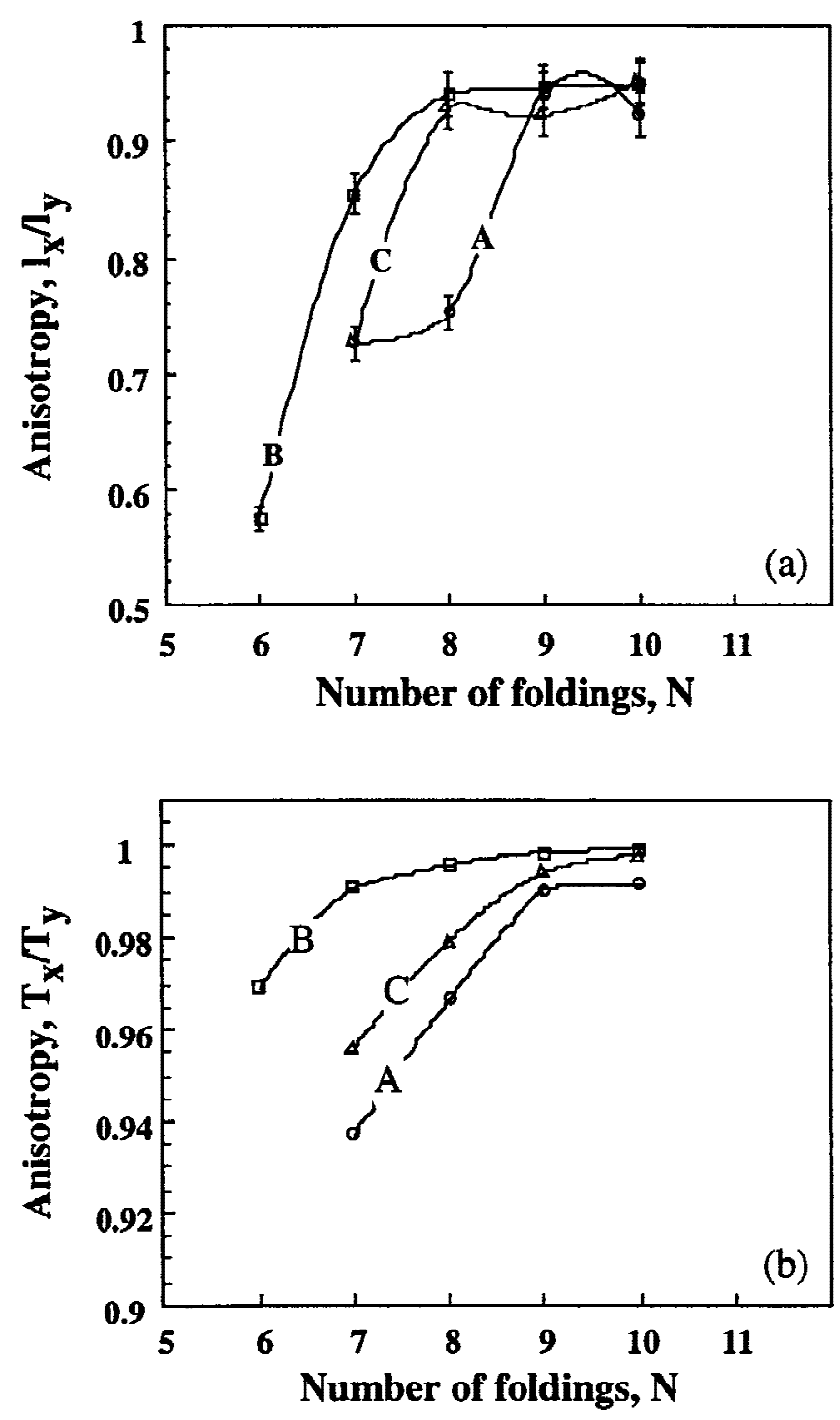

Fig. 4. Shrinkage anisotropy, evaluated using (a) the ratio of final shrinkage strains in parallel $(x)$ and perpendicular $(y)$ directions to the rolling $\left(l_{x} / l_{y}\right)$ and (b) the ratio of maximum shrinkage-rate temperatures in the $x$ - and $y$-directions $\left(T_{x} / T_{y}\right)$. When these ratios approach unity, anisotropy disappears. Note that the anisotropy decreases with the number of foldings $N$ but increases from samples B to $\mathrm{C}$ to $\mathrm{A}$.

we consider the dilute phase limit, i.e., a thin film on a thick substrate for Fig. 8(a) and a spherical inclusion in an infinite matrix for Fig. 8(d). We also assume that the two phases have the same elastic moduli. The in-plane stress in a thin layer due to shrinkage strain $\Delta$ is given by ${ }^{17}$

$$
\sigma=\frac{E \Delta}{1-v}
$$

The misfit stress in a spherical inclusion due to shrinkage mismatch in Fig. 8(b) is given by ${ }^{17}$

$$
\sigma=\frac{2}{3}\left(\frac{E \Delta}{1-v}\right)
$$

Here, $\Delta$ is the misfit strain (given by the difference in the shrinkage of the two phases), and $E$ and $v$ are the Young's modulus and Poisson's ratio, respectively. It is obvious that the spherical inclusion has a lower stress than that of a constrained film. Similar comparisons also can be made for two phases of equal volume fraction but different configurations, such as that in Figs. 8(c) and (d), with the conclusion that the constraint is reduced by replacing the laminate microstructure with the cel-

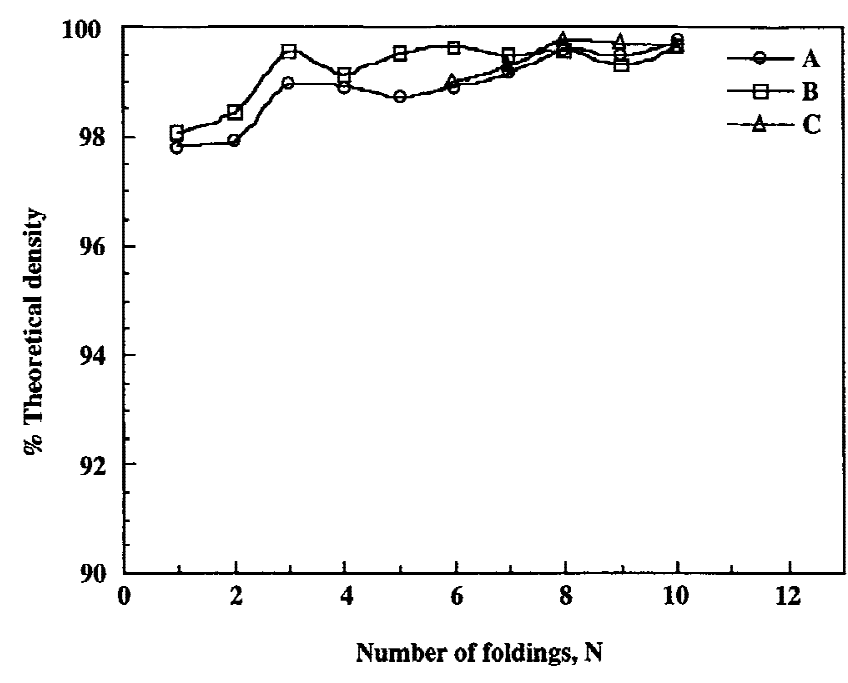

Fig. 5. Density of samples A, B, and C, plotted as a function of the number of foldings $N$.

lular microstructure. Our data indicates that the constraint stress decreases gradually as the corrugation and waviness develop and finally decreases abruptly when the phase connectivity breaks down.

\section{(2) Sintering and Thermal Cracks}

As discussed in the previous section, the Ce-TZP phase in the composite sinters faster than the $\mathrm{Al}_{2} \mathrm{O}_{3}$ phase, which leads to the development of tensile stresses in the Ce-TZP. These stresses can cause the pre-existing flaws to grow into cracks. Figure 7(a) shows that the crack spacing decreases as the layer thickness decreases, albeit with a high degree of scatter in the data. Comparison of the crack-opening displacements of the sintering cracks in Fig. 6(a), folded five times, and Fig. 6(b), folded once, indicates that cracks form earlier in the samples that have fewer foldings. These results can be explained quantitatively as follows. These cracks typically span the entire thickness of the Ce-TZP layers. As will be discussed in more detail later, thicker layers are able to store more strain energy for a tunneling crack to propagate. As these cracks develop in a layer that exceeds the critical thickness for a given misfit strain, they eventually reach a saturation spacing that scales with the critical thickness after most of the strain energy has been exhausted. As sintering misfit strain develops, the thicker layers reach the critical state of having sufficient strain energy first. Therefore, they develop cracks in the early parts of sintering, with a crack spacing that is commensurate with their thickness. These cracks collectively absorb the sintering strain of the thicker layer, so that no further cracking develops during additional sintering. Meanwhile, thinner layers do not crack until larger sintering mismatch strains develop. This phenomenon generally requires higher temperatures. After the critical condition is met, they also develop a closer crack spacing that is commensurate with their thinner layers.

Nevertheless, thinner Ce-TZP layers that are free of sintering cracks can develop thermal cracks, which have very narrow crack openings and exhibit a faint white contrast in Fig. 6(c). At the end of the sintering, which was conducted at $1600^{\circ} \mathrm{C}$ for $3 \mathrm{~h}$, all the remaining sintering stresses are expected to be relieved via diffusional smoothing; thus, the stress that is responsible for such fine cracks must originate from the thermal expansion (shrinkage) mismatch during cooling. Ce-TZP is under biaxial tensile stress when cooled, because it has a higher thermal expansion coefficient. This tensile stress, for a symmetric multilayer composite, is given by ${ }^{11,13}$

$$
\sigma=\frac{\left(\alpha_{1}-\alpha_{2}\right) \Delta T}{\frac{1-v_{1}}{E_{1}}+\frac{1-v_{2}}{E_{2}}}
$$



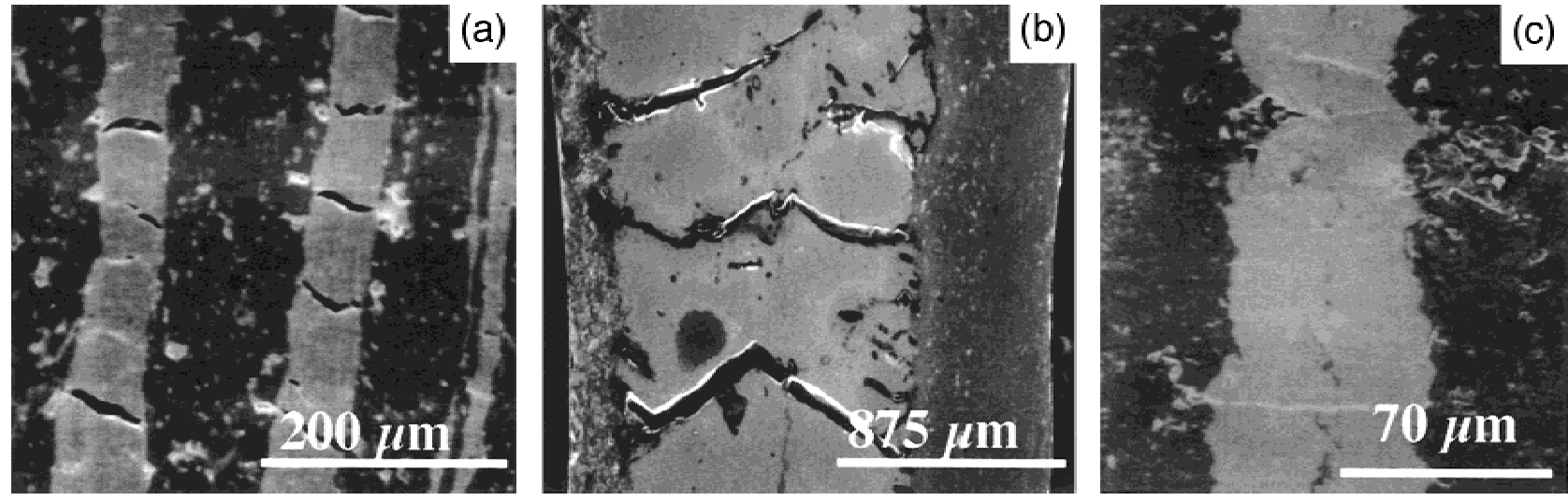

Fig. 6. Microstructures for (a) sample A folded five times, showing sintering cracks (dark and wide cracks) and cooling cracks due to thermal mismatch (thin and white lines), (b) sample B folded once, showing very wide sintering cracks, and (c) sample $\mathrm{C}$ folded five times, showing multiple tunneling cracks.

(a)

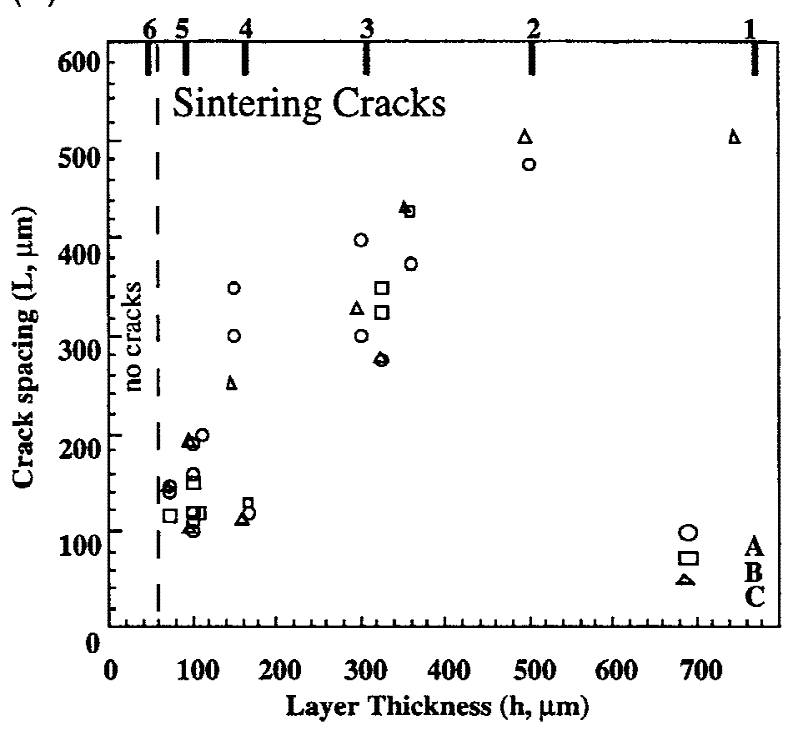

(b)

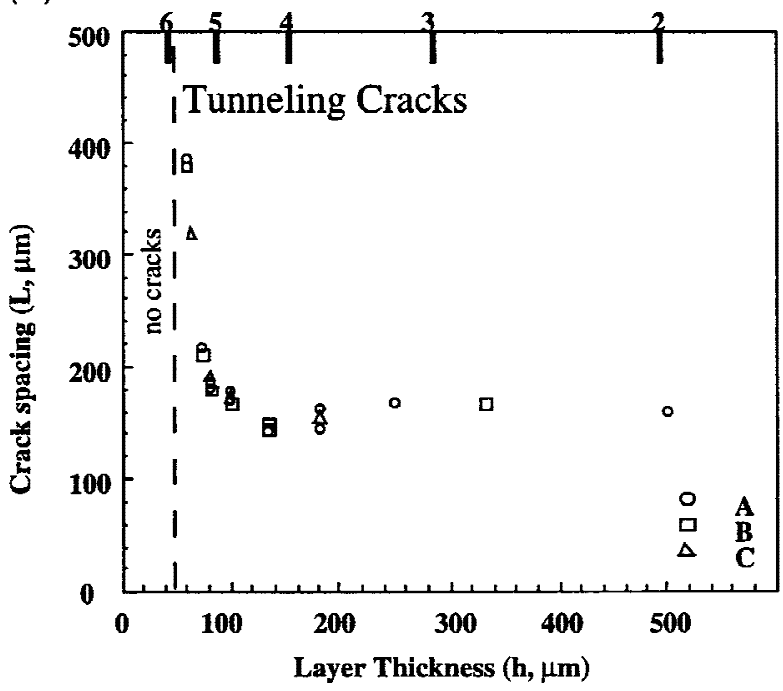

Fig. 7. (a) Sintering crack spacing as a function of layer thickness; no sintering cracks were observed below a critical layer thickness of $60 \mu \mathrm{m}$. (b) Thermal crack spacing as a function of layer thickness; no cracks were observed below a critical layer thickness of $50 \mu \mathrm{m}$. where the subscripts 1 and 2 represent the $\mathrm{Al}_{2} \mathrm{O}_{3} \mathrm{Ce}$-TZP layers, respectively; $\alpha$ is the thermal expansion coefficient, and $\Delta T$ is the temperature range over which the misfit thermal strains are frozen into the material. From the literature, ${ }^{18}$ for $\mathrm{Al}_{2} \mathrm{O}_{3}$ and $\mathrm{Ce}-\mathrm{TZP}, \alpha=8.2 \times 10^{-6}$ and $11.3 \times 10^{-6} / \mathrm{K}, E=$ 395 and $195 \mathrm{GPa}$, and $v=0.24$ and 0.32 , respectively. These values give a stress of $450 \mathrm{MPa}$ for $\Delta T=800^{\circ} \mathrm{C}$. This thermal mismatch stress monotonically increases during cooling, which causes pre-existing flaws to propagate through the layers, creating tunneling cracks. Similar tunneling cracks have been observed in layered ceramic composites, ${ }^{6,8,9,11,12}$ fiber-reinforced laminates, ${ }^{19}$ ceramic/metal intermetallic laminates, ${ }^{20}$ and during the drying of thin films. ${ }^{21}$

The small-strain, elastic-loading nature of these cracks allows us to analyze the thermal-crack data more rigorously. The crack-spacing problem of layered composites has been analyzed by Suo and co-workers. ${ }^{14,22}$ Similar problems of thinfilm cracking also have been studied by Thouless. ${ }^{23}$ According to this analysis, the critical thickness $h_{\mathrm{c}}$ of a stressed $(\sigma)$ layer at which a crack can tunnel through is given by the expression ${ }^{14}$

$$
\sigma\left(\frac{h_{\mathrm{c}}}{\bar{E} \Gamma_{\mathrm{c}}}\right)=1.128
$$

where $\Gamma_{c}$ is equivalent to the toughness of the material (the critical energy release rate) and $K_{\mathrm{IC}}^{2}=\bar{E} \Gamma_{\mathrm{c}}$ (where $K_{\mathrm{IC}}$ is the critical stress intensity factor for fracture). Note that the value on the right-hand side of Eq. (4) is not a universal constant, but rather is dependent on the elastic modulus and other boundary conditions. At higher stresses, the crack spacing also can be predicted using a graph of reciprocal normalized crack spacing, $h / L$ ( $L$ is the crack spacing and $h$ is the layer thickness), versus normalized stress, $\sigma h^{1 / 2} / K_{\mathrm{IC}}$. The crack spacing eventually saturates at an asymptotic value that is $\sim 4$ times greater than the critical layer spacing. ${ }^{23}$

Without the exact values of the constant in Eq. (4) and knowledge of the residual stress and the fracture toughness, we use the experimentally observed critical thickness, $50 \mu \mathrm{m}$, to fix the constant, giving $\sigma / K_{\mathrm{IC}}=160 \mathrm{~m}^{-1 / 2}$. Using this value, we have processed our data in the form of $h / L$ versus $\sigma h^{1 / 2} / K_{\mathrm{IC}}$, with $h$ and $L$ taken directly from Fig. 7(b), and compared it with the Hutchinson and Suo analysis. ${ }^{14}$ This comparison is shown in Fig. 9, in which Suo's prediction is drawn as a solid curve; the agreement is very good. We also note that, in Fig. 7(b), the crack spacing saturates at $\sim 150 \mu \mathrm{m}$, which is triple the critical layer thickness $(50 \mu \mathrm{m})$ for initial cracking. This observation also is in reasonable agreement with the theoretical prediction. $^{23}$

The observations of the critical thickness that is required for tunneling cracks have been made by researchers in various fields. For example, Parvizi et al. ${ }^{24}$ and Laws and Dvorak ${ }^{25}$ 


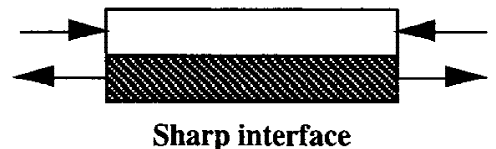

(a)

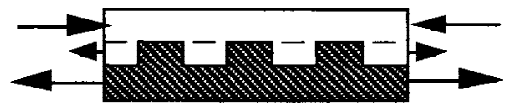

Corrugated interface

(b)

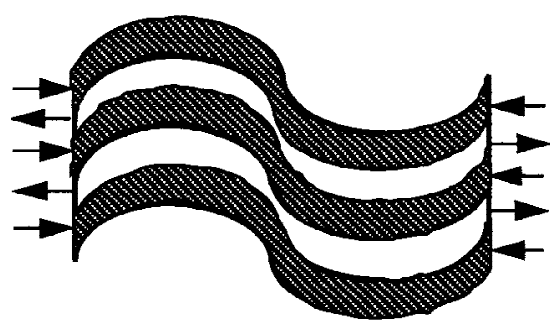

Wavy planes

(c)

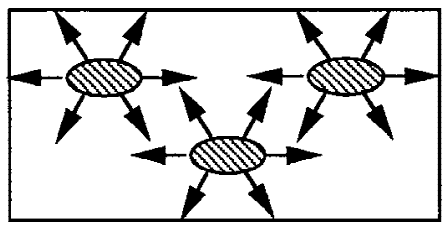

Mixed phase

(d)

Fig. 8. Sintering stress in composites with (a) a sharp interface, (b) a corrugated interface, (c) wavy planes, and (d) encased phase regions. Magnitude and direction of the stresses are illustrated schematically using arrows of different length. Stresses progressively decrease from Fig. 8(a) through Fig. 8(d).

determined a critical applied stress to grow multiple tunnels in fiber-reinforced epoxy crossply laminates. Sbaizero and Lucchini ${ }^{11}$ observed this phenomena in $\mathrm{Al}_{2} \mathrm{O}_{3} / \mathrm{ZrO}_{2}$ laminates. Kuhn-Spearing et al. ${ }^{26}$ observed similar failure modes in Strombus Gigas conch shells.

\section{Conclusions}

(1) Unblended $\mathrm{Al}_{2} \mathrm{O}_{3} / \mathrm{Ce}$-TZP laminates that are obtained using colloidal rolling techniques can be sintered to almost full density, regardless of the number of foldings and the processing history. This improved sinterability is believed to be caused by the corrugated interface and the large layer waviness, which reduces the long-range sintering stresses. Such interface features are a result of rolling instability, which is unique to these composites.

(2) The shrinkage anisotropy diminishes as the layer thickness decreases, disappearing rapidly after the laminate/cellular microstructural transition. The sintering behavior of samples with different processing histories is due to the difference in the rolling strains that is required for this transition.

(3) Sintering cracks form in the Ce-TZP layers, because of differential sintering stresses. The crack spacing increases as

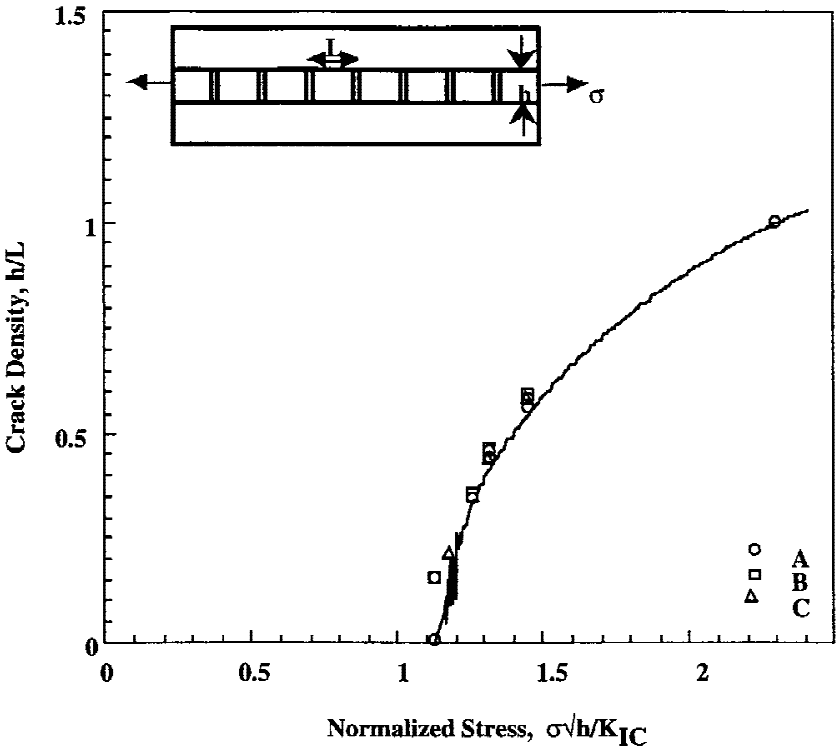

Fig. 9. Tunneling crack density for thermal cracks in Fig. 8(b), replotted as a function of normalized stress in the Ce-TZP layer. Normalized stress was estimated by determining the $\sigma / K_{\mathrm{I} C}$ ratio after substituting a critical layer thickness of $50 \mu \mathrm{m}$ in Eq. (4). Solid curve represents the prediction of the Hutchinson and Suo model. ${ }^{14}$

the layer thickness increases, and cracks form earlier in the thicker layers. No cracks form when the layer thickness is $<60$ $\mu \mathrm{m}$.

(4) The thermal expansion coefficient mismatch leads to the formation of multiple tunneling cracks within the Ce-TZP layers. The crack spacing increases as the layer thickness decreases, and no cracks form when the layer thickness is $<50$ $\mu \mathrm{m}$. This behavior has been analyzed and is consistent with the theory of Hutchinson and Suo. ${ }^{14}$

\section{References}

${ }^{1}$ T. Cheng and R. Raj, "Flaw Generation During Constrained Sintering of Metal-Ceramic and Metal-Glass Multilayered Films," J. Am. Ceram. Soc., 72 [9] 1649-55 (1989).

${ }^{2}$ R. Bordia and R. Raj, "Sintering Behavior of Ceramic Films Constrained by a Rigid Substrate,” J. Am. Ceram. Soc., 68 [6] 287-92 (1985).

${ }^{3}$ P. Nahass, W. E. Rhine, R. L. Pober, H. K. Bowen, W. L. Robbins, and C. S Draper, "A Composition of Aqueous and Non-Aqueous Slurries for TapeCasting and, Dimensional Stability in Green Tapes"; pp. 355-64 in Ceramic Transactions, Vol. 15, Materials and Processes for Microelectronic Systems. Edited by K. M. Nair, R. Pohanka, and R. C. Buchanan. American Ceramic Society, Westerville, OH, 1990.

${ }^{4}$ P. Z. Cai, D. J. Green, and G. L. Messing, "Constrained Densification of Alumina/Zirconia Hybrid Laminates, I: Experimental Observations of Processing Defects," J. Am. Ceram. Soc., 80 [8] 1929-39 (1997).

${ }^{5}$ P. Z. Cai, D. J. Green, and G. L. Messing, "Constrained Densification of Alumina/Zirconia Hybrid Laminates, II: Viscoelastic Stress Computation," J. Am. Ceram. Soc., 80 [8] 1940-48 (1997).

${ }^{6}$ D. B. Marshall, J. J. Ratto, and F. F. Lange, "Enhanced Fracture Toughness in Layered Microcomposites of $\mathrm{Ce}-\mathrm{ZrO}_{2}$ and $\mathrm{Al}_{2} \mathrm{O}_{3}$," J. Am. Ceram. Soc., 74 [12] 2979-87 (1991)

${ }^{7}$ R. K. Roeder, K. J. Bowman, and K. P. Trumble, "Texture and Microstructure Development in Platelet Reinforced $\mathrm{Ce}-\mathrm{ZrO}_{2} / \mathrm{Al}_{2} \mathrm{O}_{3}$ Laminates Produced by Centrifugal Consolidation," Textures Microstruct., 24, 43-52 (1995).

${ }^{8}$ E. Lucchini and O. Sbaizero, "Alumina/Zirconia Multilayer Composites Obtained by Centrifugal Consolidation," J. Eur. Ceram. Soc., 15, 975-81 (1995).

${ }^{9}$ T. Chartier and T. Rouxel, "Tape-Cast Alumina-Zirconia Laminates: Processing and Mechanical Properties," J. Eur. Ceram. Soc., 17, 299-308 (1997).

${ }^{10}$ K. P. Plucknett, C. H. Caceres, C. Hughes, and D. S. Wilkinson, "Processing of Tape-Cast Laminates Prepared from Fine Alumina/Zirconia Powders," $J$. Am. Ceram. Soc., 77 [8] 2145-53 (1994).

${ }^{11}$ O. Sbaizero and E. Lucchini, "Influence of Residual Stresses on the Mechanical Properties of a Layered Ceramic Composite," J. Eur. Ceram. Soc., 16, 813-18 (1996).

${ }^{12}$ T. Chartier, D. Merle, and J. L. Besson, "Laminar Ceramic Composites," J. Eur. Ceram. Soc., 15, 101-107 (1995). 
${ }^{13}$ D. Munz, M. A. Schkuhr, and Y. Yang, "Thermal Stress in Ceramic-Metal Joints with an Interlayer," J. Am. Ceram. Soc., 78 [2] 285-90 (1995).

${ }^{14}$ J. W. Hutchinson and Z. Suo, " Mixed Mode Cracking in Layered Materials," Adv. Appl. Mech., 29, 63-191 (1992).

${ }^{15} \mathrm{M}$. Menon and I-W. Chen, "Bimaterial Composites via Colloidal Rolling Technique: I, Microstructure Evolution," J. Am. Ceram. Soc., 82 [12] 3413-21 (1999).

${ }^{16} \mathrm{M}$. Menon and I-W. Chen, "Bimaterial Composites via Colloidal Rolling Techniques: III, Mechanical Properties," J. Am. Ceram. Soc., 82 [12] 3430-40 (1999).

${ }^{17}$ T. Mura, Micromechanics of Defects in Solids. Martinus Nijhoff, The Hague, The Netherlands, 1982.

${ }^{18}$ K. B. Alexander, P. F. Becher, X.-L. Wang, and C.-H. Hsueh, "Internal Stresses and the Martensite Start Temperature in Alumina-Zirconia Composites: Effects of Composition and Microstructure," J. Am. Ceram. Soc., 78 [2] 291-96 (1995).

${ }^{19}$ B. N. Cox and D. B. Marshall, "Crack Initiation in Fiber-Reinforced Brittle Laminates," J. Am. Ceram. Soc., 79 [5] 1181-88 (1996).
${ }^{20}$ T. C. Lu, J. Yang, Z. Suo, A. G. Evans, R. Hecht, and R. Mehrabian, "Matrix Cracking in Intermetallic Composites Caused by Thermal Expansion Mismatch," Acta Metall. Mater., 39 [8] 1883-90 (1991).

${ }^{21}$ S.-Y. Chen and I-W. Chen, "Cracking during Pyrolysis of Oxide Thin Films-Phenomenology, Mechanisms and Mechanics," J. Am. Ceram. Soc., 78 [11] 2929-39 (1995).

${ }^{22}$ S. Ho and Z. Suo, "Tunneling Cracks in Constrained Layers," J. Appl. Mech., 60, 890-94 (1993).

${ }^{23}$ M. D. Thouless, "Crack Spacing in Brittle Films on Elastic Substrates," J. Am. Ceram. Soc., 73 [7] 2144-46 (1990).

${ }^{24}$ A. Parvizi, K. W. Garrett, and J. E. Bailey, "Constrained Cracking in Glass Fibre-Reinforced Epoxy Cross-Ply Laminates," J. Mater. Sci., 13, 195-201 (1978).

${ }^{25}$ N. Laws and G. K. Dvorak, "Progressive Transverse Cracking in Composite Laminates," J. Compos. Mater., 22, 900-16 (1988).

${ }^{26}$ L. T. Kuhn-Spearing, H. Kesseler, E. Chateau, R. Ballarini, A. H. Heuer, and S. M. Spearing, "Fracture Mechanisms of the Strombus Gigas Conch Shell: Implications for the Design of Brittle Laminates," J. Mater. Sci., 31, 6583-94 (1996). 